\title{
POLÍTICAS DE ESTADO NO SETOR SUCROENERGÉTICO
}

\section{STATE POLICIES IN SUGARCANE SECTOR STATE POLICIES IN SUGARCANE SECTOR}

\author{
Natália Lorena Campos \\ Universidade Federal de Uberlândia (UFU), Uberlândia, MG, Brasil \\ natizinhacampos@yahoo.com.br
}

\section{RESUMO}

Muito é discutido em relação a expansão canavieira no país e quanto essa produção é vista como forma de solucionar os problemas relacionados a matriz energética brasileira. O etanol é considerado uma opção energética renovável, em substituição ao petróleo, o que faz com que sua produção seja incentivada pelo Estado. Nesse sentido, o trabalho pretende apresentar as principais políticas de Estado no setor sucroenergético e seus objetivos para a disseminação do etanol. Temos como foco a atuação dessas políticas no estado de Minas Gerais, onde a mesorregião do Triângulo Mineiro/Alto Paranaíba concentra as principais usinas no estado. Partindo do desenvolvimento agroindustrial canavieiro e as sucessivas crises neste cenário, buscamos por fim demonstrar a atual configuração do setor sucroenergético, seus avanços e retrocessos no cenário nacional.

Palavras-chave: Expansão canavieira. Políticas de Estado. Desenvolvimento agroindustrial. Minas Gerais. Setor sucroenergético.

\begin{abstract}
Much is discussed in relation to sugarcane expansion in Brazil and how this production is seen as a way of solving the problems related to the brazilian energy matrix. Ethanol is considered a renewable energy option, replacing the oil, which makes its production is State encouraged. Accordingly, the work aims to present the main State policies on sugarcane sector and its objectives to the spread of ethanol. We focus on the performance of these policies in the Minas Gerais state, where the middle region of Triangulo Mineiro/Alto Parnaiba concentrates the main plants in the state. Leaving the sugarcane agroindustrial development and the successive crises in this scenario, we seek to finally show the current configuration of the sugarcane sector, its advances and setbacks in the national scene.
\end{abstract}

Keywords: Sugarcane expasion. State policies. Agroindustrial development. Minas Gerais. Sugarcane sector.

Artigo recebido para publicação em novembro de 2014

Artigo aceito para publicação em abril de 2015

\section{INTRODUÇÃO}

Conforme a cana-de-açúcar migrou da região Nordeste adentrando os territórios do Centro-Sul do país, a partir do desenvolvimento agroindustrial canavieiro, o Estado brasileiro intensificou a criação de políticas públicas que suprimissem as necessidades dos empresários do agronegócio e a disseminação do etanol como fonte de energia renovável. Além das políticas de âmbito nacional, foram criadas políticas regionais e estaduais atendendo às necessidades de cada localidade. A expansão canavieira em Minas Gerais ocorreu, por exemplo, com maior vigor durante a década de 1980. Algumas políticas já tinham sido difundidas, como o Proálcool, e outras mais específicas para o 
desenvolvimento do Cerrado. Partindo desse princípio, buscamos analisar o desenvolvimento do agronegócio canavieiro no Brasil a partir das políticas de estado que permitiram sua expansão no país, trazendo como exemplo sua disseminação em Minas Gerais, onde a mesorregião do Triângulo Mineiro/Alto Paranaíba concentra as unidades sucroenergéticas do estado.

Outro ponto importante da pesquisa é a discussão em relação à mudança do conceito de sucroalcooleiro para sucroenergético, uma vez que a produção das agroindústrias canavieiras, cada vez mais amparadas tecnologicamente, vão além da produção do açúcar e do álcool. Essa tecnologia permitiu que as usinas também comercializassem energia e possibilitou novas funções para os subprodutos da cana-de-açúcar.

Assim, a década de 1970 permitirá compreender a configuração do setor sucroenergético no país e os principais eventos ocorridos até a crise financeira de 2008 que acometeu o setor.

\section{O desenvolvimento agroindustrial canavieiro}

O conceito de agroindústria vai além do que a nomenclatura apresenta como sendo a união entre agricultura e indústria. Essa união é a principal formadora do conceito, mas, de acordo com Belik (2007) como única interpretação, implica em comparações indevidas criando muitos problemas quando tratamos das comparações setoriais. Não podemos generalizar a atuação das agroindústrias exclusivamente em forma de setor, cada qual responsável por determinada atividade econômica, embora com essa divisão torna-se possível verificar a estrutura e determinadas relações que teriam desaparecido em uma análise dos grandes agregados.

Acerca desse fator o autor relata que "historicamente a agroindústria nasceu a partir das atividades agrícolas" e nos antigos complexos rurais ela estava presente com o beneficiamento de matérias-primas e a sua conservação. Mais recentemente, as atividades industriais realizadas no interior das fazendas passaram a ser denominadas como "indústria rural", um complemento das atividades agrárias. Anteriormente a esse processo, era complicado separar as chamadas indústrias rurais das indústrias 
propriamente dita. "As atividades industriais complementares à agricultura confundiam com a própria agricultura” (BELIK, 2007, p. 143).

O crescimento da demanda por produtos beneficiados tornou a atividade da indústria rural independente do meio agrário, deslocando-se para áreas urbanas. A agroindústria moderna não é fruto da integração para frente dos capitais agrários, mas sim através da integração para trás principalmente do capital financeiro, comercial e industrial (BELIK, 2007).

O processo de formação agroindustrial dá-se a partir de um planejamento no qual todas as etapas devem apresentar um retorno (feedback) e constituir um processo interativo. Segundo Szmerecsányi (1979) o planejamento "é um processo de intervenção racional na realidade socioeconômica que não se limita apenas à formulação de planos e programas de desenvolvimento". De acordo com o autor, os estágios do planejamento (no caso o planejamento agroindustrial) passam por algumas etapas como: a) o diagnóstico (do sistema, setor ou região) que pretende influenciar, onde são definidos os objetivos da área a ser planejada e a sua viabilidade; b) da formulação de uma política de desenvolvimento, criando diretrizes gerais e específicas para o plano; c) da elaboração do plano propriamente dito; da execução do plano; e) da avaliação periódica dos resultados obtidos e; f) a reformulação do diagnóstico, da política de desenvolvimento, dos objetivos e instrumentos do plano. O planejamento agroindustrial possui certa semelhança ao planejamento do Zoneamento Agroecológico da Cana-deaçúcar, pois procuram harmonizar as relações econômicas, sociais e ambientais no ordenamento territorial brasileiro.

Os vários subprodutos da cana-de-açúcar, todos de grande utilidade, fizeram com que a cultura canavieira tornasse uma importante atividade agrícola no país. "Devido ao seu valor de mercado, a cultura da cana-de-açúcar representa uma importante fonte de renda e de emprego para ponderáveis parcelas da população rural" (SZMERECSÁNYI, 1979, p. 41). O autor ainda ressalta que essa cultura, por outro lado, é vinculada diretamente a um grande parque fabril compreendido pelas usinas de açúcar e destilarias de álcool, o que gera renda e empregos, e cuja produção tem amplo consumo doméstico e industrial, tanto dentro como fora do País. 
O desenvolvimento do setor sucroenergético deu-se em princípio para a produção de açúcar que tinha uma crescente procura a partir do século XV, e foi um fator determinante do surto da cultura canavieira em vários países, com destaque para o Brasil.

O desenvolvimento da agroindústria canavieira teve um papel de grande relevo na história econômica do Brasil. Durante quase dois séculos após o descobrimento, ela constituiu praticamente o único pilar em que se assentava a economia colonial. Até a época, o Brasil era o maior produtor e exportador de açúcar do mundo. Daí em diante, apesar das numerosas crises havidas no subsetor, em consequência da perda da posição hegemônica do Brasil no mercado açucareiro mundial, a cana continuou sendo o principal produto comercial de sua agricultura, condição que só veio perder em fins do século passado, quando definitivamente se firmou o ciclo do café (SZMERECSÁNYI, 1979, p. 43).

Embora houvesse o surgimento de novos períodos econômicos, a cana-de-açúcar ainda era considerada uma atividade econômica importante no setor agroindustrial e ainda mantinha grande produção no Nordeste do país. O autor já destaca a crescente produção de álcool de cana, destinadas a fins carburantes e industriais, como uma importante fonte de redução e de substituição das importações de derivados do petróleo.

A produção de álcool combustível foi impulsionada pelo Estado, expandindo-se para outras regiões do país. No final do século XIX houve uma necessidade de modernização da produção para enfrentar a competição de outros países produtores, tendo o açúcar ainda como principal produto da agroindústria canavieira. A produção de álcool combustível foi incentivada a partir da década de 1970, na qual o Estado criou políticas de incentivo a essa produção. Foi nesse contexto de modernização que a região Centro-Sul vivenciou esse momento de expansão, no qual a cultura canavieira obteve sucesso nessa região.

Durante o período da modernização da agricultura iniciado na década de 1950, o Estado criou alguns importantes programas para o desenvolvimento das áreas agrícolas do Cerrado, especialmente no Triângulo Mineiro. O Sistema Nacional de Crédito Rural (SNCR) foi um dos primeiros programas com objetivo de subsidiar a agropecuária a partir de investimentos em insumos agrícolas e mecanização na 
década de 1960. Com o crédito agrícola, surgiram várias empresas agrícolas e núcleos de colonização. Em seguida, o Programa para o Desenvolvimento do Cerrado (POLOCENTRO), criado em 1975 foi bastante significativo para a região, pois acelerou o processo de transformação espacial das regiões atingidas com investimentos em infraestrutura, pesquisas agropecuárias e crédito, especializando a região atingida. Porém, o Programa Nipo-brasileiro para o Desenvolvimento do Cerrado (PRODECER) em 1978, financiado pela Agência Japonesa de Cooperação e Desenvolvimento Internacional (JICA) incentivou a colonização e usos agrícolas do Cerrado com formas de crédito supervisionado, empréstimos fundiários e de coberturas de despesas operacionais.

Os investimentos nas áreas de Cerrado intensificaram a concentração fundiária e luta pela terra, além de não ter ocorrido de forma igualitária em todos os municípios do Triângulo Mineiro. A maioria dos municípios da região que ficaram de fora do pacote tecnológico decorrente desses programas na década de 1980, encontraram no processo de expansão canavieiro uma forma de integração a economia agroindustrial. O espaço agrícola regional, que antes era marcado pela cultura de grãos e pecuária, segue agora cada vez mais tomado pelas lavouras canavieiras.

A intervenção estatal a fim de modernizar os canaviais nordestinos nas décadas de 1970/80 não teve êxito, pois a inserção de maquinário no processo produtivo impediu que a produtividade do setor aumentasse, além do descrédito dos senhores-de-engenho que perderam o controle sobre a totalidade do complexo produtivo do açúcar, base do poder político e econômico desses agentes (VIAN, 2003). Nesse contexto, a região Centro-Sul começou a receber suas primeiras unidades de produção e as primeiras lavouras. Dentre elas, estavam unidades oriundas do Nordeste - algumas filiais de empreendimentos tradicionais do Nordeste que viram um potencial de desenvolvimento na região, expandindo seu capital. Essa expansão deu-se não apenas devido ao descrédito dos produtores nordestinos, mas também devido às constantes secas, estas que motivaram o envolvimento de novas áreas, e até mesmo a transferência de algumas unidades para o Centro-Sul.

O estado de São Paulo e algumas regiões do Paraná formaram o primeiro cenário da produção canavieira no Centro-Sul. Essa produção obteve grande desenvolvimento fazendo com que elas 
tornassem as maiores produtoras de açúcar e álcool do país. Tem-se aí o desenvolvimento do setor sucroalcooleiro, voltado à produção de açúcar (prefixo sucro) e/ou álcool (sufixo alcooleiro), diretamente relacionado às culturas de cana-de-açúcar, principal insumo para o processo produtivo do açúcar e do álcool, além de mais vantajoso em relação aos outros insumos utilizados para a produção em outros países, como o milho e a beterraba. A Tabela 1 apresenta a comparação dessas outras fontes em relação à cana-de-açúcar.

\begin{tabular}{lccc}
\hline \multicolumn{1}{c}{ Matéria-prima } & Cana-de-açúcar & Milho & Beterraba \\
\hline \multicolumn{1}{c}{ Região } & Brasil & Estados Unidos & União Europeia \\
\hline $\begin{array}{l}\text { Custo de Produção } \\
(\text { USD/litros) }\end{array}$ & 0,21 & 0,27 & 0,76 \\
$\begin{array}{l}\text { Balanço Energético } \\
\text { Redução das emissões }\end{array}$ & 9,3 & 1,4 & 2,0 \\
de GEE (em \%) & 90 & 35 & 34 \\
\hline
\end{tabular}

Tabela 1. Comparação das fontes alternativas na produção do etanol Fonte: UNICA, 2011/ SIAMIG, 2011. Org.: CAMPOS, N. L., 2014.

Temos que a produção de etanol através da cana-de-açúcar como matéria prima se mostra mais vantajosa economicamente em relação ao seu custo de produção, redução das emissões de GEE (Gases do Efeito Estufa), eficiência energética e produtividade.

\section{Do setor sucroalcooleiro ao setor sucroenergético: uma nova abordagem}

O conceito de setor sucroalcooleiro vem perdendo sentido a partir do momento em que a produção de derivados da cana vai além do açúcar e do álcool. Com o desenvolvimento tecnológico é possível produzir energia elétrica (bioenergia), plástico e o bio-hidrocarboneto que está sendo desenvolvido como um combustível de aviação, o que seria uma espécie de diesel da cana. Sendo assim, o conceito passa por inúmeras mudanças ao longo do tempo devido às inúmeras possibilidades de produção a partir da cana-de-açúcar. Com ela, além da produção de agrocombustíveis como o etanol, e a produção de açúcar, novas tecnologias estão sendo desenvolvidas. Com isso, o sentido de setor sucroalcooleiro não cabe como definidor, haja vista que o número de produtos finais vai além do que esse setor produz. 
Nesse sentido, adotamos o conceito sucroenergético substituindo o sucroalcooleiro, pois ele engloba tanto a produção de açúcar como a produção de fontes energéticas (etanol e agroenergia).

Com o avanço tecnológico, foi possível a produção de energia elétrica a partir do bagaço e da palha da cana, que antes eram considerados resíduos sem finalidade e ainda evita a queima que já está praticamente eliminada nos canaviais. Além da produção de energia, uma nova matéria já vem sendo produzida a partir da cana-de-açúcar. Trata-se do bioplástico, feito a partir da moagem da cana que produz o suco, fermentado e destilado em etanol, que é convertido por uma série de processos químicos, para se tornar um monoetilenoglicol, um derivado de petróleo que é misturado em um ácido (tereftálico) para criar o plástico pet. Esse pet é utilizado nas garrafas de $600 \mathrm{ml}$ da Coca-Cola. Uma tecnologia que ainda está em desenvolvimento é a do bio-hidrocarboneto ${ }^{1}$, que será um novo combustível voltado à aviação. É devido a essa gama de possibilidades de produção a partir da cana que segundo Dantas (2008) se deve adotar o termo cana energética em substituição ao termo cana-deaçúcar.

As projeções indicam um aumento da participação relativa da venda de energia na receita das usinas em detrimento da receita oriunda da comercialização de açúcar. A comercialização de energia corresponderá a $2 / 3$ da receita das usinas já na safra 2015/16. Desta forma, torna-se adequada à utilização do termo cana energética em substituição ao termo cana de açúcar. Por fim, é necessário se ressaltar a necessidade de se adotar a expressão sucroenergético em detrimento ao termo sucroalcooleiro porque já é passado o tempo em que o etanol era o único bem energético produzido nas usinas canavieiras brasileiras (DANTAS, 2008, s/p).

Segundo Camelini; Castillo (2012), a adoção desse termo tornou mais coerente numa referência à sua importância para a matriz energética, visto que, "além da participação direta do etanol no abastecimento de veículos, secundariamente à sua produção é possível extrair a chamada "bioeletricidade", ou seja, eletricidade obtida por meio da biomassa do bagaço da cana" (CAMELINI; CASTILLO, 2012, p. 10).

\footnotetext{
${ }^{1}$ Diesel da cana-de-açúcar. Combustível de aviação (SIAMIG, 2011).
} 
Muitas usinas já produzem energia capaz de sustentar todo seu processo produtivo e ainda vender o excedente para as companhias energéticas. Essa produção de energia deu-se em meados dos anos 1990, período em que as usinas passaram a investir em novas caldeiras capazes de um melhor rendimento a partir do bagaço e da palha da cana. A expectativa é que a produção de energia tende a superar a de açúcar nas usinas.

Segundo especialistas, a cana-de-açúcar gera $1 / 3$ de vinhaça, $1 / 3$ de palha e $1 / 3$ de bagaço. Ou seja, pode-se usar 2/3 para a produção de energia elétrica. A estimativa é que em 2020 a produção nacional de cana-de-açúcar atinja um bilhão de toneladas - hoje são 496 milhões de toneladas. Com esta projeção a produção de energia elétrica através das usinas deverá igualar a produção da Usina Hidrelétrica de Itaipu, que tem capacidade instalada de produção de 14 mil megawatts (MW) (REVISTA RURAL, 2008, s/p).

Na figura 1 temos um esboço do que é produzido a partir da cana-de-açúcar e algumas tecnologias que ainda estão em desenvolvimento como o bioplástico, o qual a usina Santa Vitória Açúcar e Álcool pretende construir um polo integrado de produção de polietileno a parir da cana-de-açúcar, e o biohidrocarboneto.

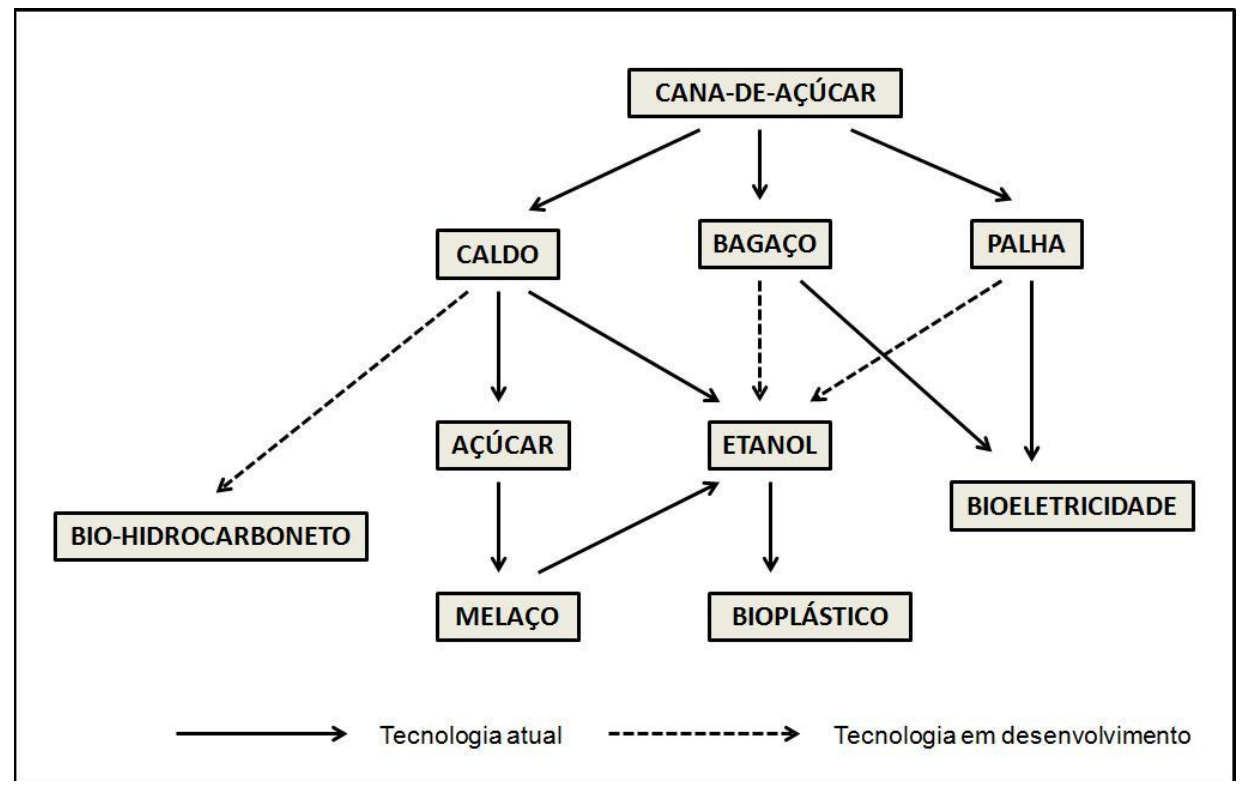

Figura 1. Processo produtivo a partir da cana-de-açúcar Fonte: SIAMIG, 2011, adaptado pela autora.

Org: CAMPOS, N. L., 2013. 
Através da cana-de-açúcar é extraído o caldo o bagaço e a palha. Deles é possível a produção do açúcar, do melaço, do etanol, da bioeletricidade, do bioplástico e futuramente o bio-hidrocarboneto (subprodutos da cana). A produção está dividida em três etapas básicas: plantação e cultivo da canade-açúcar, produção do açúcar ou álcool e a comercialização do produto final. Tem seu início no campo (cana-de-açúcar) até chegar ao mercado (produto final).

No campo, o que vem a ser importante é a disponibilidade e o custo das terras, assim como as condições edafoclimáticas, o custo dos insumos, o crédito para o custeio da produção, a realização de um perfil agrário e histórico agrícola da região, as variedades de cana, a mão-de-obra qualificada, tecnologia e seguir as legislações (florestal, ambiental trabalhista e propriedade). A logística agroindustrial é necessária, considerando a topografia, as chuvas, o crédito, a disponibilidade de máquinas, tecnologia e a mão-de-obra qualificada. Na etapa correspondente a indústria-produção são considerados a qualidade da matéria prima, os preços relativos, a capacidade industrial, a manutenção da fábrica assim como chuva, mão-de-obra qualificada e tecnologia. No estoque deve se pensar na sazonalidade, na capacidade de estocagem, nas condições financeiras, contratos e estratégias de compra e venda. Assim, tem-se a etapa do transporte do produto final, no qual o preço do frete, a destinação e a localização da indústria são determinantes, e por fim, o mercado, verificando o crescimento econômico, o câmbio, os aspectos ambientais e sociais, a produção mundial, as chuvas, a inflação e o preço da gasolina e do petróleo (SIAMIG, 2011).

Essas etapas são importantes para o desenvolvimento e funcionamento do setor, pois são condicionantes à produção dos derivados da cana. Campo, logística agroindustrial, indústria-produção, estoque, transporte-produto final e mercado são os principais processos produtivos que fazem parte das etapas do planejamento da produção agroindustrial e ainda estão envolvidos em uma rede agroindustrial que dinamizam a produção.

\section{As crises do petróleo e a dinâmica agroindustrial a partir da década de 1970}


Durante a década de 1970, com a crise no mercado mundial de açúcar e devido à pressão a respeito da necessidade de preservação dos recursos naturais e a escassez de petróleo (Primeiro Choque do Petróleo), surgiu à preocupação mundial em relação à forma de produção e consumo de uma nova fonte de energia. Com isso, tem-se o intento dos combustíveis alternativos, menos prejudiciais ao meio ambiente e que suprissem a necessidade mundial, podendo ser uma alternativa para a matriz energética do país.

Embora o etanol como combustível seja considerado uma fonte de energia limpa, menos prejudicial ao meio ambiente, sua produção traz inúmeras implicações em relação às questões ambientais além de expulsar os trabalhadores do campo e ameaçar a produção de alimentos. Segundo Fabrini (2010), o processo de modernização da agricultura e a incorporação de novas terras à dinâmica capitalista provocaram a expulsão de milhares de pequenos proprietários, rendeiros, ribeirinhos, caiçaras, posseiros, quilombolas, dentre outros, como camponeses e indígenas de suas terras.

Mesmo levantando questões que implicam na contestação do modelo agroindustrial, a demanda por combustíveis cresceu vertiginosamente, sobretudo, os alternativos devido às crises que ocorreram durante a década de 1970 em relação ao petróleo. Como forma de incentivar o setor, o Instituto do Açúcar e do Álcool - IAA, junto ao governo federal, criou o Programa Nacional de Melhoramento da Cana-de-açúcar - PLANALSUCAR para renovar as variedades de cana produzidas no país. Nesse sentido, a importância da relação indústria e agricultura permitiram o sucesso da produção do etanol graças aos subsídios creditícios e incentivos fiscais.

\footnotetext{
O processo de integração indústria e agricultura não se deu à margem das relações entre as grandes empresas, os grupos econômicos e o Estado. Este último atuou, sobretudo, através de subsídios creditícios, incentivos fiscais e toda uma bateria de políticas incentivadoras das exportações (MÜLLER, 1989, p. 18).
}

Essa integração indústria-agricultura foi denominada por Müller (1989) de complexo agroindustrial, no qual a produção agrária não se dá apenas na dependência das solicitações do comércio, mas também 
de um conjunto de indústrias que tem nas atividades agrárias seus mercados. Para Müller, o complexo agroindustrial

[...] é uma forma de unificação das relações interdepartamentais com os ciclos econômicos e as esferas da produção, distribuição e consumo, relações essas associadas as atividades agrárias Vale dizer que o complexo agroindustrial é considerado como uma unidade analítica da acumulação de capital no país (MÜLLER, 1989, p. 23).

Foi nos anos de 1970 e a partir dos desdobramentos economicamente positivos da união entre indústria e agricultura que o Estado brasileiro criou o Programa Nacional do Álcool - PROÁLCOOL (1975-1985) como forma de aumentar a produção de etanol e incentivar o seu uso. O etanol (ou álcool etílico) é produzido em usinas a partir de matérias-primas como cana-de-açúcar, milho ou beterraba. No Brasil a produção se dá pela cana-de-açúcar por ser mais rentável e fácil de produzir, no qual é produzido o álcool anidro e o hidratado. $\mathrm{O}$ anidro é utilizado como aditivo em combustíveis, composto por $99,5 \%$ de álcool puro e $0,5 \%$ de água. Sua concentração na gasolina é de $25 \%$ de acordo com a EMBRAPA. O hidratado é utilizado como combustível composto por $96 \%$ de álcool puro e 4\% de água, utilizado no Brasil desde 1979 (EMBRAPA, 2011).

O etanol é um agrocombustível, ou seja, um combustível renovável, que não precisa de materiais de origem fóssil, como o petróleo. Seu processo de produção inicia-se pela moagem da cana, onde se obtém o caldo que contém alto teor de sacarose. O próximo passo (segunda etapa) é a produção do melaço a partir do aquecimento do caldo da cana. É nesta etapa que o açúcar é produzido. A terceira etapa é de fermentação do melaço. Nela fermentos biológicos são acrescidos ao melaço fazendo com que a sacarose se transforme em etanol. A última etapa é a destilação do mosto fermentado onde se obtém $96 \%$ de etanol e 4\% de água.

\begin{tabular}{|l|l|}
\hline Momento & \multicolumn{1}{|c|}{ Característica } \\
\hline $\mathbf{1 9 7 3}$ & Primeiro choque do petróleo \\
$\mathbf{1 9 7 4}$ & Brasil cria o Proálcool \\
$\mathbf{1 9 7 7}$ & Adição de $4,5 \%$ de etanol à gasolina \\
$\mathbf{1 9 7 9}$ & Adição de $15 \%$ de etanol à gasolina \\
$\mathbf{1 9 8 0}$ & Segundo choque do petróleo \\
\hline
\end{tabular}




\begin{tabular}{|c|l|}
\hline $\mathbf{1 9 8 3}$ & Carros a etanol representam $90 \%$ do total de vendas \\
$\mathbf{1 9 8 5}$ & Percentual de etanol adicionado à gasolina chega a $22 \%$ \\
$\mathbf{1 9 8 9}$ & Preços do petróleo caem e gasolina se equipara ao etanol \\
$\mathbf{1 9 9 0}$ 's & Etanol passa a representar de $20 \%$ a $25 \%$ da gasolina \\
$\mathbf{2 0 0 3}$ & Lançamento dos carros bicombustíveis \\
$\mathbf{2 0 0 5}$ & É lançado o programa nacional de Biodiesel \\
$\mathbf{2 0 0 7}$ & Terceiro choque do petróleo \\
$\mathbf{2 0 0 8}$ & Início da obrigatoriedade do B2 \\
Abril de 2008 & Consumo do etanol se equipara ao da gasolina \\
Julho de $\mathbf{2 0 0 9}$ & Vigência do B4 \\
& ANP passa a regular e fiscalizar a produção de etanol, agora considerado um \\
Abril de $\mathbf{2 0 1 1}$ & combustível. Percentual na gasolina pode ir de 18 a $25 \%$ e é determinado pelo \\
& governo \\
\hline
\end{tabular}

Quadro 1. Principais fases da produção de agrocombustíveis no Brasil (1973-2011)

Fonte: Adaptado da ANP, 2011.

Org.: CAMPOS, N. L., 2011.

O etanol produzido pode ser usado na fabricação de bebidas como para combustível, o que é feito no Brasil. Essa preferência é pelo fato de o etanol produzir 89\% menos de CO2 que a gasolina. Além disso, o etanol brasileiro é considerado um etanol avançado por alcançar as normas de emissão de CO2 definidas pelo Protocolo de Kyoto. No quadro 1 temos um breve resumo da evolução dos agrocombustíveis no Brasil.

A partir dessa evolução, percebemos os interesses dos representantes agroindustriais canavieiros em tornar o etanol um combustível competitivo na matriz energética brasileira. Nesse sentido, os investimentos em políticas públicas para o setor tiveram significativo aumento e importância a partir da década de 1970.

\section{Principais fases do Programa Nacional do Álcool - PROÁLCOOL}

O Proálcool foi um programa classificado como bem-sucedido oficialmente implantado no governo Geisel, em 1975, no período da ditadura militar, com o objetivo de estimular a produção de álcool em substituição a gasolina, derivada do petróleo e que estava passando por grave crise econômica, por ser um combustível não-renovável, podendo esgotar-se. A intenção do programa era reduzir as 
importações de petróleo. A produção de álcool a partir da cana-de-açúcar tem maior retorno econômico para os agricultores por hectares plantados do que pela mandioca, beterraba ou qualquer outro insumo, e com a baixa do preço do açúcar no mercado internacional, a mudança de produção, do açúcar para o álcool, tornou-se mais atrativa à economia.

A implantação do Proálcool foi precedida de um forte debate entre os atores envolvidos, a saber, Cooperativa Central dos Produtores de Açúcar e Álcool do Estado de São Paulo (Copersucar), Sindicato dos Produtores de Álcool de São Paulo, Cooperativa Fluminense de Produtores de Açúcar e Álcool (Coperflu), Associação Brasileira das Indústrias Químicas, associações de produtores de cana de vários estados e o IAA, além de técnicos da Petrobrás (VIAN, 2003, p. $85)$.

Houve embates em relação à implantação de destilarias anexas ou autônomas ${ }^{2}$. O IAA defendia a expansão canavieira através das destilarias autônomas, incentivando sua implantação em regiões de fronteira, a fim de trabalhar com a capacidade ociosa nas usinas. Já a Copersucar era a favor da produção de anidro através das destilarias anexas, pois as destilarias paulistas trabalhavam com capacidade ociosa e havia excesso de cana para ser esmagada. Para solucionar esse embate, o documento "Fotossíntese como Fonte Energética" sugeriu a implantação do Proálcool utilizando a capacidade ociosa das usinas paulistas e sua expansão futura via destilarias autônomas, conjugando os interesses dos defensores do anidro e do hidratado. Assim, permitia-se a ocupação da capacidade ociosa das usinas paulistas e a expansão de álcool em destilarias autônomas. O Proálcool é classificado por diferentes fases e períodos econômico no Brasil.

Sua primeira fase corresponde de 1975 a 1979. Nesse período, surgiram os primeiros automóveis movidos exclusivamente a álcool. A fase foi marcada por fortes investimentos do Estado em destilarias anexas, devido ao crescimento na produção de álcool anidro para ser misturado à gasolina. Os estados tradicionais na produção açucareira - São Paulo e Alagoas foram os mais beneficiados e Pernambuco, Rio de Janeiro e Minas Gerais se destacaram no número de projetos de destilarias anexas segundo Bray, Ferreira e Ruas (2000). Nessa fase do Proálcool o número de destilarias autônomas e anexas

${ }^{2}$ Destilarias anexas: ou vinculadas às usinas e geralmente localizadas junto a estas; autônomas: ou não-vinculadas a usinas e localizadas nos, ou junto aos grandes centros de consumo (Ver SZMERECSÁNYI, 1979, p. 82).

${ }^{3}$ Trabalho publicado por grupos paulistas e alguns representantes da Associação dos Produtores e distribuidores de Gás (ASSOCIGÁS) apregoando as vantagens do álcool como combustível e da cana como sua matéria-prima 
aumentou juntamente com a produção de álcool, o que objetivou dinamizar o Proálcool. O IAA incentivou a produção de álcool anidro "estipulando o preço de paridade em 44 litros de álcool por saca de 60 quilos de açúcar, o que fazia com que fosse indiferente para a usina produzir um ou outro produto" (VIAN, 2003, p. 87). Foram criadas linhas de crédito subsidiado e garantias de compra do produto.

Sua segunda fase corresponde ao período do Segundo choque do petróleo (1979), mais significativo em relação ao seu impacto negativo à economia mundial. Nesse período houve uma maior necessidade na produção de álcool combustível com foco maior para a produção do hidratado. Como políticas para o setor foram criados o Conselho Nacional do Álcool - CNAL e a Comissão Executiva Nacional do Álcool - CENAL como organismos para agilizar o Proálcool. Os créditos de subsídios continuaram e foi estipulada uma produção de 60 mil litros/dia para as destilarias continuarem recebendo os subsídios.

A opção pela produção do álcool em destilarias possui um custo menor do que nas usinas (cerca de 20\%) de acordo com Alcântara Filho e Silva (1981). Foi em sua segunda fase que o programa deslanchou e obteve sucesso com a crescente produção de álcool. Nessa fase, o incentivo era à implantação de destilarias autônomas e a produção de álcool era mais rentável em relação a de açúcar.

O Governo Federal tinha o objetivo de aumentar e garantir a oferta de álcool anidro incentivando a instalação de novas unidades produtoras, dado que com a produção concentrada em destilarias anexas existia o risco do não cumprimento das metas de produção, uma vez que as mesmas podiam produzir mais açúcar, diminuindo o volume de álcool no momento em que o preço do primeiro no mercado externo era mais compensador. Isso ocorria porque as usinas ainda viam o álcool apenas como um subproduto da produção de açúcar (VIAN, 2003, p. 87).

Nessa fase, houve um crescimento de unidades instaladas no Oeste e Nordeste de São Paulo, em Goiás e no Triângulo Mineiro/Alto Paranaíba. "Entre 1981 e 1985 foram implantadas novas destilarias, principalmente em regiões que eram marcadas pela presença de latifúndios com pecuária extensiva de corte no estado de São Paulo" (VEIGA FILHO; RAMOS, 2006, p. 50). 
As usinas tradicionais tinham mais de 50 anos no negócio e os novos empresários atingiram maiores índices de produção e produtividade. Houve ainda incentivo por parte dos Governos Federal e Estaduais na compra de carros movidos a álcool, reduzindo o IPI, além da isenção de impostos e taxas para taxistas que optassem pelo uso de carros a álcool.

Em sua fase de estagnação (de 1985 a 1995) o Brasil passou a produzir e vender um grande número de automóveis movidos a álcool, alcançando uma marca de $95,8 \%$ de toda a frota vendida. No mesmo período, o preço do barril de petróleo cai ("contrachoque do petróleo"), fazendo com que os consumidores voltassem ao uso da gasolina, o que coincide com um período de escassez de recursos públicos no Brasil para subsidiar a produção do etanol. Houve uma queda nos índices de produção de etanol e corte dos subsídios, o que chamamos de desregulamentação do setor, devido aos baixos preços pagos aos produtores, o que não relaciona com a demanda pelo combustível por parte dos consumidores, que ainda era estimulada e subsidiada pelo Estado. Vale ressaltar que a ausência de recursos se dava apenas ao setor sendo que o uso do álcool combustível ainda era incentivado pelo Estado.

Como forma de intervenção no setor, a Sociedade, Produto, Açúcar e Álcool - SOPRAL iniciou uma discussão a respeito da postura do IAA, que deveria ser uma agência reguladora, deixando as atividades de comercialização e financiamento a cargo dos agentes, retirando o controle da comercialização do álcool e do açúcar das associações das entidades de representação, minimizando os conflitos e denúncias de favorecimento de certas empresas.

Estados como Mato Grosso, Paraná, Goiás e Mato Grosso do Sul conseguiram o fim das cotas de produção, liberando a entrada de novos fabricantes e minimizando os efeitos da crise sobre as destilarias autônomas instaladas.

No início dos anos 90 as características estruturais básicas do complexo canavieiro brasileiro podiam ser assim resumidas: produção agrícola e fabril sob controle dos usineiros, heterogeneidade produtiva (especialmente na industrialização da cana), aproveitamento baixo de 
subprodutos, competitividade fundamentada, em grande medida, nos baixos salários e na expansão extensiva. As diferenças eram enormes quando se comparava o Nordeste com o Centro-Sul. Mas mesmo nessa última região existiam diferenças acentuadas de produtividade e escala de produção (VIAN, 2003, p. 100).

Vian (2003) aponta a desregulamentação do complexo e as tentativas posteriores de auto regulação que culminaram com a consolidação da União da Agroindústria Canavieira de São Paulo - ÚNICA, primeiramente como uma entidade de representação dos interesses desse estado, como principal fato ocorrido na década de 1990. Nesse período surgiram algumas restrições novas no complexo.

\footnotetext{
Com medidas de cunho liberalizante, o Estado iniciou a década de 1990, se retirando, gradativamente, do centro das decisões acerca do setor, deixando-o nas mãos da iniciativa privada. Essa retirada do governo do controle das atividades do setor alcooleiro foi o que caracterizou seu processo de desregulamentação, ou seja, processo no qual o Estado deixou de regulamentar a produção, estoque, comercialização e preços do setor (PEREIRA, 2007, p. 59).
}

Durante sua fase de estagnação, houve uma redução da participação estatal nas decisões do setor. Isso fez com que ocorressem mudanças na forma de comercialização e no estabelecimento dos preços do álcool, além da perda da credibilidade dos carros movidos a álcool e no consumo do produto. A estagnação do setor foi consequência da ausência de políticas públicas específicas para o mesmo.

Durante o governo Collor, em 1990, o IAA foi extinto. A extinção do IAA foi a primeira medida de desregulamentação promovida pelo Estado que envolvia o setor, e mais tarde a liberalização dos preços dos seus produtos. Houve uma estabilidade da produção e descrédito do setor devido a falta do álcool, o que fez com que muitas usinas quebrassem e outras mudassem o foco de produção para o açúcar. Ainda em 1990, foi eliminado o incentivo concedido pelo Estado de redução do IPI para automóveis movidos a álcool e a frota desses veículos diminuiu.

No entanto, o Estado ainda acreditava na eficiência do álcool como combustível e com isso passou a estimular sua produção a partir da medida provisória $n^{0} 1.662$ de 28 de maio de 1998, no qual o percentual de adição de álcool anidro à gasolina tornasse obrigatório de 22 até $24 \%$, e como forma de 
utilização do álcool combustível os preços do etanol e da gasolina foram equiparados. Foi nesse período que houve a inserção do capital estrangeiro.

Com a extinção do IAA, o controle e o planejamento do setor ficaram a cargo da Secretaria de Desenvolvimento Regional da Presidência da República e, posteriormente, com o Conselho Interministerial do Álcool - CIMA, presidido pelo Ministério da Indústria e do Comércio até 1999, quando passou para o Ministério da Agricultura. A indefinição quanto ao órgão responsável pela regulamentação do setor foi uma das causas da lentidão quanto à adoção de novas regras de gestão e de políticas específicas para o álcool (VIAN, 2003, p. 101).

A crise na produção do álcool combustível afetou a credibilidade do Proálcool, que entrou numa fase de redefinição (1995 a 2000). A quantidade de cana-de-açúcar produzida no Brasil manteve estável entre 2 e 3 milhões de toneladas como observado na tabela 2.

\begin{tabular}{cccc}
\hline Anos & Brasil & Minas Gerais & $\begin{array}{c}\text { Triângulo Mineiro/ } \\
\text { Alto Paranaíba }\end{array}$ \\
\hline $\mathbf{1 9 9 0}$ & 262.674 .150 & 301.710 & 103.862 \\
$\mathbf{1 9 9 1}$ & 260.887 .893 & 277.284 & 87.987 \\
$\mathbf{1 9 9 2}$ & 271.474 .875 & 272.709 & 81.976 \\
$\mathbf{1 9 9 3}$ & 244.530 .708 & 264.344 & 78.436 \\
$\mathbf{1 9 9 4}$ & 292.101 .835 & 263.696 & 86.084 \\
$\mathbf{1 9 9 5}$ & 303.699 .497 & 267.571 & 92.575 \\
$\mathbf{1 9 9 6}$ & 317.105 .981 & 247.290 & 69.789 \\
$\mathbf{1 9 9 7}$ & 331.612 .687 & 279.063 & 97.818 \\
$\mathbf{1 9 9 8}$ & 345.254 .972 & 279.449 & 105.753 \\
$\mathbf{1 9 9 9}$ & 333.847 .720 & 280.331 & 110.694 \\
\hline
\end{tabular}

Tabela 2. Quantidade produzida de cana-de-açúcar em toneladas (1990 a 1999)

Fonte: Produção Agrícola Municipal (PAM), 2014.

Org.: CAMPOS, N. L., 2014.

Em Minas Gerais a produção canavieira teve uma pequena diminuição e no Triângulo Mineiro/Alto Paranaíba percebemos um pequeno crescimento na produção canavieira, que aumentara nos anos 2000 junto ao processo de expansão das usinas na região.

Toda ação que se tentava atribuir ao setor nesse período não funcionava e geravam críticas entre os produtores e entidades responsáveis. Uma tentativa de autogestão setorial mal sucedida foi a 
distribuição de cotas de exportação pelas associações de produtores (Associação das Indústrias de Açúcar e Álcool - AIAA e SOPRAL). Segundo Vian (2003), os grupos empresariais desentenderamse quanto à metodologia de concessão de cotas para os vários grupos. Tem-se como falha a tentativa de atribuir cotas a todas as empresas produtoras de açúcar, fazendo com que aquelas que não tinham excedentes para exportação serem beneficiadas comercializando suas cotas.

Nessa fase de organização do setor, o Estado tratou de criar entidades de regulação para fiscalizar as atividades do setor, bem como garantir sua representação no governo. Nesse sentido, merecem destaque o Conselho Nacional do Açúcar e do Álcool - CIMA, em 1997, com o objetivo de direcionar políticas para o setor sucroenergético e a Agência Nacional do Petróleo - ANP, em 1997, que, no que se refere ao álcool, exerce atividades relacionadas a fiscalização da distribuição e a revenda desse produto (PEREIRA, 2007, p. 69). Um fator que condicionou no processo de desregulamentação do setor foi a ausência da intervenção estatal, no qual algumas empresas não conseguiram se adaptar ao livre mercado, quebrando.

Com a desregulamentação e liberalização dos preços a partir de 1995, surgiram novas distribuidoras de pequeno e médio porte, aumentando o grau de concorrência neste mercado. Dentre essas distribuidoras, destacam-se grandes grupos, alguns de origem familiar, presentes principalmente no Centro-Sul, como Copersucar, Crystalsev, Cosan, São Martinho, Irmãos Biagi, João Lyra, Tércio Wanderley, Nova América e Carlos Lyra. Alguns desses grupos estão presentes em Minas Gerais, destacando-se na produção canavieira.

O Quadro 2 resume as principais fases da agroindústria canavieira no Brasil a partir do final do século XIX até o pós-1990, destacando os principais eventos deflagradores, as políticas adotas e os resultados, por vezes satisfatórios, outras não.

Período
Eventos deflagradores
Estratégias adotadas

Resultados 


\begin{tabular}{|c|c|c|c|}
\hline $\begin{array}{l}\text { Final do século } \\
\text { XIX }\end{array}$ & $\begin{array}{l}\text { Crises de superprodução. } \\
\text { Perda de participação } \\
\text { relativa no mercado externo } \\
\text { para produtores mais } \\
\text { modernos. Emergência do } \\
\text { protecionismo europeu } \\
\text { (Antilhas, Europa). }\end{array}$ & $\begin{array}{l}\text { Desvalorização cambial, } \\
\text { subsídios para implantação } \\
\text { de "engenhos centrais", } \\
\text { surgimento de "usinas". }\end{array}$ & $\begin{array}{l}\text { "Engenhos centrais" } \\
\text { falham. Apenas as usinas } \\
\text { atingem o objetivo de } \\
\text { aumentar a eficiência da } \\
\text { produção. }\end{array}$ \\
\hline $1905 / 07$ & $\begin{array}{l}\text { Conflitos entre usinas e } \\
\text { refinadoras/comerciantes } \\
\text { sobre o preço interno do } \\
\text { açúcar. }\end{array}$ & $\begin{array}{l}\text { Coligação do açúcar de } \\
\text { Pernambuco e Coligação do } \\
\text { açúcar do Brasil. }\end{array}$ & $\begin{array}{l}\text { Estabilização dos preços } \\
\text { por dois anos-safra. } \\
\text { Comportamento } \\
\text { oportunista de usineiros de } \\
\text { Campos (RJ) inviabilizou a } \\
\text { manutenção do acordo. }\end{array}$ \\
\hline $1929 / 33$ & $\begin{array}{l}\text { Crise } \\
\text { mundial/superprodução de } \\
\text { açúcar. Litígios internos } \\
\text { (usina x fornecedor, disputa } \\
\text { de mercado entre PE e SP). }\end{array}$ & $\begin{array}{l}\text { Pesquisas e incentivo ao } \\
\text { álcool. Criação do IAA } \\
\text { (cotas de produção, controle } \\
\text { dos preços). }\end{array}$ & $\begin{array}{l}\text { Controle da produção } \\
\text { nacional e estabilização dos } \\
\text { preços. }\end{array}$ \\
\hline $1939 / 45$ & $\begin{array}{l}\text { Guerra mundial e problemas } \\
\text { com abastecimento de } \\
\text { gasolina e açúcar no Brasil. }\end{array}$ & Incentivo ao "álcool-motor". & $\begin{array}{l}\text { Aumento da produção } \\
\text { paulista. }\end{array}$ \\
\hline $1959 / 62$ & $\begin{array}{l}\text { Revolução Cubana. } \\
\text { Problemas sociais no } \\
\text { Nordeste e erradicação dos } \\
\text { cafezais em SP. }\end{array}$ & $\begin{array}{l}\text { Tentativa de modernização } \\
\text { da produção nordestina. }\end{array}$ & $\begin{array}{l}\text { Exportação para os EUA. } \\
\text { Crescimento da produção } \\
\text { paulista. }\end{array}$ \\
\hline $1974 / 75$ & $\begin{array}{l}\text { Queda dos preços mundiais } \\
\text { do açúcar. Primeiro choque } \\
\text { do petróleo. }\end{array}$ & Lançamento do Proálcool. & $\begin{array}{l}\text { Crescimento da produção } \\
\text { de álcool anidro. }\end{array}$ \\
\hline $1979 / 83$ & $\begin{array}{l}\text { Segundo choque do petróleo. } \\
\text { Estimativas quanto ao } \\
\text { esgotamento das reservas de } \\
\text { óleo. }\end{array}$ & Reforço do Proálcool. & $\begin{array}{l}\text { Crescimento da produção } \\
\text { de álcool hidratado. }\end{array}$ \\
\hline $1985 / 89$ & $\begin{array}{l}\text { Reversão dos preços do } \\
\text { petróleo, crise nas finanças } \\
\text { públicas e falta de álcool. }\end{array}$ & $\begin{array}{l}\text { Investimentos na produção } \\
\text { nacional de petróleo. }\end{array}$ & $\begin{array}{l}\text { Quebra da confiança no } \\
\text { álcool combustível. }\end{array}$ \\
\hline Pós-1990 & $\begin{array}{l}\text { Extinção do IAA. (Brasil: } \\
\text { maior produtor mundial x } \\
\text { protecionismo/subsídios, } \\
\text { fontes e alternativas } \\
\text { energéticas). Superprodução } \\
\text { de álcool. Reestruturação } \\
\text { produtiva: questão social e } \\
\text { ambiental. }\end{array}$ & $\begin{array}{l}\text { Medidas paliativas: pacto } \\
\text { pelo emprego, Brasil álcool, } \\
\text { bolsa brasileira de álcool. } \\
\text { Auto-gestão setorial: } \\
\text { Consecana, grupos de } \\
\text { comercialização e redução do } \\
\text { número de entidades de } \\
\text { representação patronal. }\end{array}$ & $\begin{array}{l}\text { Preços e mercados } \\
\text { instáveis. Redução no uso } \\
\text { de mão-de-obra e } \\
\text { intensificação da } \\
\text { mecanização da } \\
\text { agricultura. Fusões, } \\
\text { entrada de empresas } \\
\text { estrangeiras e emergência } \\
\text { de novas estratégias. }\end{array}$ \\
\hline Década de 2000 & $\begin{array}{l}\text { Criação dos automóveis } \\
\text { bicombustíveis (flexfuel). } \\
\text { Aumento na instalação de } \\
\text { unidades produtoras de } \\
\text { etanol no país. }\end{array}$ & $\begin{array}{l}\text { Incentivos à produção de } \\
\text { etanol. Estudos delimitando } \\
\text { áreas com maior aptidão na } \\
\text { produção canavieira. }\end{array}$ & $\begin{array}{l}\text { Aumento do uso de etanol } \\
\text { como combustível } \\
\text { doméstico. Crises na } \\
\text { produção canavieira e } \\
\text { aumento no preço do } \\
\text { etanol. }\end{array}$ \\
\hline A partir de 2008 & $\begin{array}{l}\text { Crise mundial de } 2008 . \\
\text { Enfraquecimento do setor }\end{array}$ & $\begin{array}{l}\text { Estímulo a fusão entre } \\
\text { empresas. Presença do }\end{array}$ & $\begin{array}{l}\text { Reativação de usinas pós } \\
\text { crise. Aumento da área de }\end{array}$ \\
\hline
\end{tabular}




\begin{tabular}{|l|l|l|l|}
\hline & $\begin{array}{l}\text { sucroenergético. Quebra de } \\
\text { usinas. }\end{array}$ & $\begin{array}{l}\text { capital externo. Políticas de } \\
\text { criação de linhas especiais de } \\
\text { crédito para o setor. }\end{array}$ & $\begin{array}{l}\text { produção da cana-de- } \\
\text { açúcar. Aumento na } \\
\text { produção de etanol. }\end{array}$ \\
\hline
\end{tabular}

Quadro 2. Principais fases das estratégias políticas da agroindústria canavieira do Brasil (Séculos XIX e XX)

Fonte: Adaptado de Belik et al. (1998), atualizado pela autora. Org.: CAMPOS, N. L., 2013.

Os eventos ocorridos propiciaram a configuração do cenário agroindustrial canavieiro no Brasil, que em diferentes momentos econômicos do país teve uma política específica para solucionar os problemas ocorridos em relação a produção de combustíveis no país e no cenário mundial.

Nos anos recentes vivenciamos uma nova expansão da monocultura canavieira no país. Após a fase de desregulamentação e reestruturação do setor na década de 1990, a dinâmica do complexo canavieiro passou a uma organização setorial em campos organizacionais. As empresas investiram em maior produtividade e menores custos de produção. Nesse sentido, houve o surgimento de novos produtos, novos segmentos de mercado para os já existentes, e novas técnicas de produção, que fez com que a estrutura do setor alterasse para uma estrutura heterogênea.

Os interesses comuns ao complexo canavieiro, como o papel do álcool como combustível líquido, tributação, meio ambiente, cogeração de energia e abertura de mercados externos, permitiram sua estabilidade atual.

[...] o complexo fragmenta-se pelo lado técnico e produtivo e torna-se coeso pelo lado institucional, algo nunca visto anteriormente no Brasil. As disputas pelo acesso privilegiado ao Estado e às entidades de representação foram substituídas pelas ações conjuntas e coordenadas no âmbito institucional. Mas ainda persistem algumas disputas regionais que precisam ser resolvidas para que não voltem a causar crises sistêmicas (VIAN, 2003, p. 132).

A fragmentação do complexo agroindustrial em campos organizacionais foi marcada pelo retorno do capital estrangeiro adquirindo empresas e formalizando parcerias, visando à produção e a comercialização do açúcar. Durante a implementação do Proálcool, o objetivo da intervenção estatal era o de equilibrar os mercados evitando o desabastecimento e as variações bruscas de preços. Na fase 
pós-desregulamentação, o que predomina é a concorrência empresarial na busca de inovações tecnológicas e na produção em terras de boa qualidade que apresentam vantagens comparativas e boa logística. Isso se deve aos custos mais baixos e lucro acima da média.

Temos nessa fase o investimento por parte das empresas, direcionados à especialização da produção através do uso dos subprodutos da cana, o que não ocorria nos anos 1980, no qual os investimentos se limitavam em melhores condições técnicas para seus equipamentos. Vian (2003) aponta como possibilidades de melhor aproveitamento das economias de diversificação produtiva, a cogeração de energia, que só deslanchou com a crise energética. A produção de energia pelas usinas já é uma realidade comum em muitas empresas do Centro-Sul. Muitas empresas mineiras já inseriram a produção de energia em seu processo produtivo e a utiliza para auto consumo e ainda vendem o excedente.

Outras questões importantes no período pós-desregulamentação do setor foram as preocupações sociais e ambientais. O Governo do Estado de São Paulo proibiu em 1997 a queima total da cana como forma de conservação e preservação do solo, e de evitar prejuízos à saúde. A ação deveria ser implementada em oito anos nas áreas onde a colheita poderia ser mecanizada e em quinze anos nas áreas onde a topografia impedia o uso de máquinas colheitadeiras. A questão da queima da cana já foi reduzida consideravelmente, uma vez que os investimentos na mecanização do plantio e colheita intensificaramse. As empresas que respeitassem as medidas em relação à queima da cana e proibição de mão-de-obra infantil receberiam uma certificação "socioambiental”. Essa certificação é utilizada pelas empresas como uma forma de garantir aos seus consumidores a compra de produtos que não agridam o meio ambiente, não utilizam mão-de-obra infantil e que estão em dia com todos os direitos trabalhistas de seus funcionários.

Foi durante o segundo mandato do governo Fernando Henrique Cardoso (1998-2002) que surgiram os automóveis bicombustíveis - movidos a álcool e/ou gasolina, os chamados carros flexfuel. Com isso, os investimentos no setor foram retomados e o plantio da cana-de-açúcar para a produção do etanol avançou para além das áreas tradicionais (interior paulista e Nordeste), alcançando os Cerrados. 
Nesse período houve um crescimento significativo de novas unidades além de unidades reativadas em todo o país. Muitas usinas criaram uma destilaria anexa para a produção do etanol. Minas Gerais se insere nesse contexto como uma nova área de expansão da monocultura canavieira no Brasil. Com essa expansão, a produção canavieira obteve um crescimento no país. Esse crescimento foi significativo no período de 2000 a 2009 passando dos 3 milhões de toneladas/ano pra mais de 6,5 milhões de toneladas/ano (PAM-IBGE, 2011).

\begin{tabular}{|c|c|c|c|c|c|}
\hline \multicolumn{2}{|c|}{$\begin{array}{c}\text { MOAGEM DE CANA-DE- } \\
\text { ACCÚCAR }\end{array}$} & \multicolumn{2}{|c|}{ PRODUÇÃO DE ETANOL } & \multicolumn{2}{|c|}{ PRODUÇÃO DE AÇÚCAR } \\
\hline Estado & Moagem (t) & Estado & Produção $\left(\mathrm{m}^{3}\right)$ & Estado & Produção (t) \\
\hline $1^{0}$ São Paulo & 329.923 & $1^{\circ}$ São Paulo & 11.830 & $1^{\circ}$ São Paulo & 23.289 \\
\hline $2^{0}$ Goiás & 52.727 & $2^{\circ}$ Goiás & 3.130 & $2^{\circ}$ Minas Gerais & 3.418 \\
\hline $3^{\circ}$ Minas Gerais & 51.759 & $3^{\circ}$ Minas Gerais & 1.994 & $3^{0}$ Paraná & 3.086 \\
\hline $4^{0}$ Paraná & 39.726 & $4^{0}$ Mato G. do Sul & 1.917 & $4^{\circ}$ Alagoas & 2.221 \\
\hline $5^{0}$ Mato G. do Sul & 37.330 & $5^{\circ}$ Paraná & 1.299 & $5^{\circ}$ Goiás & 1.875 \\
\hline $6^{0}$ Alagoas & 23.401 & $6^{\circ}$ Mato Grosso & 975 & $6^{0}$ Mato G. do Sul & 1.742 \\
\hline \multicolumn{2}{|c|}{ TOTAL BRASIL $(*)=588.370$} & \multicolumn{2}{|c|}{ TOTAL BRASIL $(*)=23.209$} & \multicolumn{2}{|c|}{ TOTAL BRASIL $(*)=38.237$} \\
\hline
\end{tabular}

(*) Estimativa

Tabela 3: Produção canavieira nos principais estados do Brasil (2013)

Fonte: SIAMIG, 2014, adaptada pela autora.

Segundo estimativas da SIAMIG para a safra 2013/2014 Minas Gerais aparece em segundo lugar no ranking de moagem de cana-de-açúcar e produção de açúcar, e terceiro lugar na produção de etanol como pode ser visualizado nas estimativas presentes na Tabela 3 .

\section{Crise de 2008 e a nova configuração no setor sucroenergético}

O ano de 2008 foi marcado por uma forte crise mundial que afetou a economia do setor canavieiro. Momentos antes da ocorrida crise, o setor canavieiro estava otimista com os elevados índices de produção de etanol e expansão das áreas de cultivo incentivadas pelo aumento da demanda de carros flex, o que fez com que o setor contraísse dívidas para aumentar a produção do etanol. No entanto, outros fatores junto à crise mundial corroboraram com o enfraquecimento do setor. Condições climáticas com chuvas elevadas alternando com períodos de seca, contratempos econômicos e 
financeiros e ausência de uma política setorial direcionada fizeram com que muitas usinas e produtores quebrassem. Muitas usinas tiveram grandes perdas cambiais e aumentaram muito o seu endividamento. Descapitalizadas, a saída encontrada por elas foi reestruturar-se financeira e societariamente. Assim, essas empresas necessitaram contrair mais dívidas, "estima-se que um terço do setor tenha mergulhado em dificuldades" (BRASIL REAL, 2011). Alguns impactos foram observados no setor sucroenergético: i) escassez de financiamentos internos e externos; ii) elevado custo financeiro dos recursos para investimentos; iii) perdas cambiais e elevado endividamento de algumas usinas e; iv) diminuição das exportações de etanol em função da retração da demanda no exterior (GOES; MARRA, 2009, p. 3).

Com a baixa produção de etanol, o país se viu na necessidade de importar o combustível para suprimir a demanda que o crescimento de automóveis bicombustíveis gerou. Além disso, para minimizar os custos, as usinas não renovaram seus canaviais, o que fez com que a produtividade caísse. Uma medida encontrada pelos usineiros foi optar pela produção do açúcar que era mais rentável no período.

Para superar os problemas ocorridos no setor sucroenergético e minimizar os efeitos da crise, houve uma intervenção estatal onde a Petrobrás aumentou sua participação no setor. O objetivo do Estado é “tornar-se sócio de empresas que hoje vendem açúcar e forçá-las a produzir etanol, de maneira a aumentar a oferta e, assim, baixar os preços (BRASIL REAL, 2011).

O apoio estatal para o agronegócio inclui constante rolagem de bilhões de reais em dívidas, incentivos fiscais, crédito a juros subsidiados e segurança de mercado, através de acordos internacionais de comércio e da retomada dos incentivos para a produção de agrocombustíveis. Essa política ganhou força a partir de 2004, quando houve uma forte queda do preço da soja no mercado internacional e grandes produtores foram salvos pelo Programa Nacional de Biocombustíveis. $\mathrm{O}$ mesmo ocorreu com as usinas de cana - muitas estagnadas ou falidas desde a extinção do Instituto do Açúcar e do Álcool, em 1990 - que "ressuscitaram" com a injeção de novos recursos públicos para a produção de etanol (RELATÓRIO DA REDE SOCIAL DE JUSTIÇA E DIREITOS HUMANOS, 2012). 
A medida encontrada pelo governo Dilma (2011-2014) foi aumentar o percentual de etanol à gasolina de 20 para $25 \%$ e uma proposta de conceder total isenção de impostos para a produção de etanol. 0 papel do capital financeiro e das empresas multinacionais no agronegócio canavieiro ajudou o setor a enfrentar a crise. O Grupo Cosan é um exemplo da captação de recursos do mercado financeiro, além da presença de grupos estrangeiros como a British Petroleum (BP), a Archer Daniels Midland (ADM) e a Bunge com atuação no Triângulo Mineiro/Alto Paranaíba e outras regiões do país. "A atuação dos fundos de investimento no setor ocorre tanto através da aquisição completa de usinas quanto da associação ou fusão" (RELATÓRIO DA REDE SOCIAL DE JUSTIÇA E DIREITOS HUMANOS, 2012).

Segundo o Relatório (2012), a crescente participação de empresas multinacionais no setor gera maior concentração de capitais e, aparentemente, está relacionada com a busca por investimentos tidos como "saudáveis", considerando-se uma suposta estabilidade no mercado de terras no Brasil. Porém, o movimento de concentração de capitais decorre da própria crise econômica mundial.

Especialistas afirmam que o setor precisa se reorganizar e buscar no planejamento estratégico setorial uma visão de longo prazo que determine as competências essenciais que mereçam investimentos, uma vez que os mesmos terão que ser seletivos. Algumas medidas estão sendo criadas pelo Estado a fim de superar a crise financeira como a "fusão de grupos empresariais, visando a capitalização e o escalonamento das dívidas num horizonte de longo prazo já está acontecendo entre grupos nacionais estrangeiros" (GOES; MARRA, 2009, p. 4). O momento enfrentado pelo setor sucroenergético fez com que despertasse a atenção de investidores externos que estão altamente interessados e apostando na expansão internacional do etanol e que o setor sucroenergético vive um momento atípico.

Outra medida encontrada pelo Estado foi a criação de uma linha especial de crédito pelo Banco Nacional de Desenvolvimento Social (BNDES) para financiamentos ao setor e já foram utilizados no primeiro bimestre de 2009 o montante de 1,5 bilhão de Reais para as usinas. A previsão é de que estes recursos cheguem a 7 bilhões de Reais em 2009. "A maior parte desses recursos têm sido utilizados para financiar fusões e aquisições. E a Petrobrás Biocombustíveis (PBIO) anunciou para o período 
2009/2013 "investimentos da ordem de 2,4 bilhões de reais, dos quais 1,9 bilhões de reais serão destinados ao etanol. Desse total de 2,4 bilhões de reais, 945 milhões de reais serão investidos em 2009, 91\% serão investidos no Brasil e 9\% no exterior" (GOES; MARRA, 2009, p. 5).

Nesse sentido e de acordo com o Sindicato da Indústria de Fabricação do Álcool no Estado de Minas Gerais - SIAMIG, o desafio é manter o etanol como uma fonte energética competitiva frente às demais existentes. Com o desenvolvimento tecnológico, as empresas estão produzindo além do já tradicional açúcar e álcool, energia e plástico utilizando os subprodutos da cana (caldo, bagaço e palha).

\section{CONSIDERAÇÕES FINAIS}

Elevar a produção do etanol a uma nova matriz energética em substituição ao petróleo, promover a cogeração de energia e conquistar o mercado internacional são as principais metas do setor sucroenergético brasileiro, porém, alguns contratempos ocorreram, e o alcance dessas metas cada vez mais necessitam de novas estratégias de desenvolvimento.

Entre os anos de 2007 e 2011, o país contou com a instalação de mais 382 novas plantas agroindustriais de açúcar e álcool, sendo elas implantadas em São Paulo, Goiás e Minas Gerais, concentrando $72 \%$ desses investimentos. Havia uma expectativa de crescimento da produção de álcool com a manutenção da vanguarda tecnológica, entre outras iniciativas, a formação e capacitação de profissionais especializados e a consolidação e aumento da frota de veículos flex, permitindo a estabilização dos preços graças ao poder de optar pelo combustível e com a sua evolução de vendas, tornou-se o pilar de sustentação da demanda por etanol. Nesse sentido, investimentos em expansão foram incentivados durante os dois mandatos do governo Lula (2002-2010).

O período foi marcado por diversas fusões e aquisições, que foram consideradas previsíveis, pois o setor estava em pleno desenvolvimento e essas fusões favoreceram novos investimentos e trouxeram credibilidade para o setor junto aos compradores externos. 0 mercado externo é outra meta em que o 
setor sucroenergético visa alcançar. Os investimentos de grupos estrangeiros facilitaram o alcance ao mercado externo.

Podemos considerar então que a década de 2000 foi marcada por grandes investimentos no setor sucroenergético, tanto nacionais como internacionais, em pesquisas nos setores agrícola e industrial e na busca por novas áreas de expansão. Isso deve-se a valorização do etanol, como uma das principais fontes de energia limpa, uma vez que o mundo passou a reconhecer a necessidade de mudar sua matriz energética, até agora baseada quase que exclusivamente em combustíveis fósseis. Essa mudança visa primordialmente à minimização das consequências danosas do efeito estufa, por meio da utilização de fontes de energias renováveis, em atendimento às disposições estabelecidas no protocolo de Quioto, do mecanismo de desenvolvimento limpo.

Outro marco importante alcançado pelo setor sucroenergético foi a cogeração de energia a partir do bagaço e da palha. Durante um cenário de crise energética no país, essa tecnologia veio para fortalecer a atividade canavieira. $O$ preço do açúcar no mercado externo também foi grande motivador para esse fortalecimento.

No entanto, o que parecia propício ao agronegócio canavieiro, nos últimos anos, durante o governo Dilma (2011-2014), o setor vem enfrentando sucessivas crises e falta de incentivo estatal, o contrário das atitudes tomadas no governo Lula, causando insatisfação aos empresários do agronegócio que atribuem ao atual governo praticar uma política equivocada que causou um retrocesso no programa de etanol. Tal atitude foi duramente criticada devido a oscilação na produção de etanol e um forte aumento das exportações de petróleo. Houve um aumento de mais de $66 \%$ no consumo de gasolina e de queda de mais de $22 \%$ no consumo do etanol entre os anos de 2009 a 2012, segundo o Secretário Executivo do Ministério do Meio Ambiente ${ }^{4}$. Ele destacou que o cenário vai contra o Programa Brasileiro de Mudanças Climáticas, que prevê um aumento de 11\% no consumo do etanol entre os anos de 2008 e 2018.

\footnotetext{
${ }^{4}$ João Paulo Capobianco.
} 
Outras críticas direcionadas ao atual governo referem-se principalmente à ênfase na produção de energias renováveis. Ao discriminar contra as energias renováveis, o governo Dilma "alavancou as emissões de gases do efeito estufa, aumentando brutalmente a carbonização da economia brasileira" (VEIGA, 2014), na contramão do desenvolvimento sustentável.

Segundo as críticas, as ações praticadas pelo governo Dilma prejudicaram a cadeia do etanol do Brasil que estava conseguindo transformar vantagens comparativas em vantagens competitivas no atual âmago da sustentabilidade: a descarbonização. Assim, a competitividade do etanol foi severamente comprometida pelas políticas de preços e tributos favoráveis aos combustíveis fósseis. Muitas usinas fecharam e outras enfrentam fortes quedas de faturamento.

O cenário atual se divide por partes otimistas em relação à expansão do cultivo da cana-de-açúcar. 0 aumento dos índices de produtividade, novos projetos de implantação de usinas demonstram essa satisfação; e por partes pessimistas, pois muitas usinas no Brasil iniciarão a próxima safra (2014/15) descapitalizadas e sem perspectivas de expansão. Devido a essa situação, algumas empresas ameaçam fechar, pois estão altamente endividadas e não conseguiram superar a crise de 2008. Segundo reportagem ${ }^{5}$, algumas das tradicionais famílias de usineiros cederam espaço para grupos internacionais, que se aproveitaram da fragilidade financeira das companhias para entrar no setor. Cerca de 40 grupos estão em recuperação judicial e dezenas de unidades foram desativadas.

No mercado de etanol, a situação também é alarmante. Com a política do governo de segurar o preço da gasolina para conter a inflação, o combustível verde perdeu competitividade. E as descobertas do pré-sal deixaram o etanol de escanteio. Para conter tal situação, as companhias estão adotando uma política de disciplina financeira.

Nesse sentido, a visão de Flexor (2009) cabe muito bem para o atual momento vivenciado pelo setor sucroenergético. Comparada à efervescente conjuntura pré-crise, o momento atual é marcado por expectativas menos grandiosas ou alarmantes, e por um ambiente intelectual mais propício à revisão da

\footnotetext{
${ }^{5}$ Portal NovaCana, fevereiro de 2014.
} 
percepção dos desafios e problemas do setor, cuja discussão está mais associada agora a aspectos mais concretos e operacionais. Esse momento, no entanto, não perdurará e, mais cedo ou mais tarde, "aquelas controvérsias anteriores a respeito da segurança alimentar ou do desmatamento das florestas tropicais voltarão a ocupar um lugar de destaque na agenda global do século XXI".

\section{REFERÊNCIAS}

BELIK, W. Agroindústria e política agroindustrial no Brasil. In: Pedro Ramos [et al]. Dimensões do agronegócio brasileiro: politicas, instituições e perspectivas. Brasília: MDA, 2007, 360 p. p.141-170.

BRASIL REAL. A séria crise do etanol brasileiro. CARTAS DE CONJUNTURA ITV - nº 83 - Set, 2011.

CAMELINI, J. H.; CASTILlO, R. Etanol e uso corporativo do território. Mercator. Fortaleza, v. 11, n. 25, p. 7-18, 2012.

DIREITOS humanos no Brasil. SYDOW, E., MENDONÇA, M. L. (Orgs.) Relatório da Rede Social de Justiça e Direitos Humanos. São Paulo, 2009, 278 p.

FABRINI, J. E. O campesinato frente à expansão do agronegócio e do agrocombustível. In: SAQUET, M. A., SANTOS, R. A. (Orgs.) Geografia Agrária, território e desenvolvimento. 1ª Ed. São Paulo: Expressão Popular, 2010, p. 55-88.

FLEXOR, G. Os desafios dos biocombustiveis em tempo de crise econômica. Artigos Mensais OPPA. Rio de Janeiro. N. 25, p. 1-3, 2009.

GOES, T.; MARRA, R. 2009-2010 - Setor sucroenergético frente a crise mundial. EMBRAPA, 2009. Disponível em: $<$ www.embrapa.br>. Acesso em: 15 jul. 2013.

MICHELOTTO, B. D. G. Novos arranjos territoriais. A expansão da cultura da cana-de-açúcar na região do Triângulo Mineiro - MG. 2008. 156 f. Dissertação de Mestrado (Centro de Desenvolvimento Sustentável) - Universidade de Brasília UnB, 2008.

MULLER, G. Complexo agroindustrial e modernização agrária. São Paulo: HUCITEC, 1989. 149 p.

PEREIRA, G. T. V. O setor alcooleiro: da rígida intervenção ao processo de regulamentação. 2007.85 f. Monografia. Departamento de Ciências econômicas, UFSC/ Florianópolis, 2007.

Sindicato da Indústria de Fabricação do Álcool no Estado de Minas Gerais - SIAMIG. Disponível em: $<$ http://www.siamig.org.br/>. Acesso em: 22 jun. 2014.

SUCROENERGIA - Movida à cana. REVISTA RURAL. Rev. 130, dez. 2008. Disponível em: $<$ www.revistarural.com.br $>$. Acesso em: 11 jul. 2014.

SZMRECSÁNYI, T. O planejamento da agroindústria canavieira do Brasil (1930-1975). São Paulo: HUCITEC/UNICAMP, 1979.540 p.

VEIGA FILHO, A. A.; RAMOS, P. Proálcool e evidências de concentração na produção e processamento de cana-de-açúcar. Informações Econômicas, São Paulo, n. 7, jul. 2006, p. 48-61.

VIAN, C. E. F. Agroindústria canavieira: estratégias competitivas e modernização. Campinas: Átomo, 2003. 216 p. 